Pesq. Vet. Bras. 30(2):186-189, fevereiro 2010

Tópico de Interesse Geral

\title{
Gato doméstico: futuro desafio para controle da raiva em áreas urbanas? ${ }^{1}$
}

\author{
Gelson Genaro²*
}

\begin{abstract}
Genaro G. 2010. [Domestic cat: Future challenge for the control of urban rabies?] Gato doméstico: futuro desafio para controle da raiva em áreas urbanas? Pesquisa Veterinária Brasileira 30(2):186-189. Programa de Pós-Graduação em Psicobiologia da Faculdade de Filosofia Ciências e Letras de Ribeirão Preto da Universidade de São Paulo, Ribeirão Preto, SP 14001-970, Brazil. E-mail: ggenaro@ ffclrp.usp.br

This article aims to promote a debate over the actual and (possibly) future increasing relevance of the domestic cat concerning public health, with emphasis on rabies (animal/ urban) control. Scientific literature on the specific role played by cats, especially with respect to zoonoses is scarce. This species is becoming the most popular pet in the western urban context. This is particularly because of the lifestyle adopted by the population, who live in smaller houses and have little time available for pet care, relegating dogs to a less preferential position. Cats do not predominate as domestic animals in Brazil yet, but if these animals soon become the preferential pets in our country, strategies adopted during anti-rabies vaccination campaigns will need to be reviewed. Furthermore, the ethological features of the domestic felid will have to be considered, so that a more suitable approach for the vaccination of the recommended number of animals can be established.
\end{abstract}

INDEX TERMS: Rabies, zoonoses, domestic animals, cat.

RESUMO.- O objetivo deste artigo foi introduzir debate a respeito da presente e, possivelmente, da futura relevância crescente do gato doméstico, no que se refere à saúde pública, com ênfase para a raiva (animal/urbana). A literatura científica que trata do papel específico do gato em relação às zoonoses ainda é reduzida. Essa espécie está se tornando o mais popular animal de companhia no mundo ocidental urbano, particularmente devido ao estilo de vida adotado pelas pessoas, com reduzido espaço residencial e pouco tempo disponível para se dedicarem aos animais de companhia, o que prejudica especialmente o cão, animal, até então, preferencial. A predominância do gato ainda não é observada no Brasil, contudo, se, em breve, ela for aqui reproduzida ter-se-á que rever as es-

\footnotetext{
${ }^{1}$ Recebido em 5 de outubro de 2009.

Aceito para publicação em 21 de dezembro de 2009.

2 Programa de Pós-Graduação em Psicobiologia, Faculdade de Filosofia Ciências e Letras de Ribeirão Preto, Universidade de São Paulo, Cx. Postal 390, Centro, Ribeirão Preto, SP 14001-970, Brasil. "Autor para correspondência: ggenaro@ffclrp.usp.br
}

tratégias adotadas, particularmente nas campanhas de vacinação antirrábica. E as características etológicas do felino doméstico deverão ser consideradas para se estabelecer estratégias mais adequadas para que se vacine 0 número de animais recomendado.

TERMOS DE INDEXAÇÃO: Raiva, zoonoses, animais domésticos, gato.

\section{INTRODUÇÃO}

Como afirmam Neto \& Pasternak (2008) “... há muito para catalogar e investigar nos nossos problemas de saúde pública, até porque se não o fizermos, ninguém o fará e vamos continuar copiando normas de outros lugares...", logo, há necessidade de constante atualização e revisão das prioridades, nos diferentes níveis, para a tomada de decisões nos sistemas de saúde, com necessidade de refinado acompanhamento e, na medida do possível, antecipar-se a essas possíveis tendências.

Muitos dos problemas de saúde pública, relacionados à raiva, no Brasil, já estão satisfatoriamente equacionados, 
contudo, essa situação não é estanque, logo, propostas de novas abordagens precisam ser embasadas em pesquisas atuais. A raiva é, ainda hoje, grave problema de zoonose, entretanto, sua importância é relativa, segundo o local estudado, observando-se situações diametralmente opostas como: encontra-se erradicada em alguns países e em outros (por exemplo, na Índia) há situação preocupante ainda registrada, e vários países do Continente SulAmericano vivem situação preocupante (Schneider et al. 1996, Passos et al. 1998, Miranda et al. 2003). Para o Brasil, o controle da raiva urbana é primordial, pois controlá-la na forma silvestre é quase impossível, dada à intensa circulação nessa forma (Schneider et al. 1996).

A literatura científica que trata do papel específico do gato doméstico em relação às zoonoses ainda é bastante restrita. Grisi-Filho et al. (2008) estimam população canina de 1.490 .500 e felina de 226.954 para a cidade de São Paulo, com densidade populacional de 987,74 cães e 150,40 gatos por $\mathrm{km}^{2}$. Ou seja, ainda hoje se observa papel mais importante para o cão, e as ações são basicamente voltadas para esse animal, justificadamente. Entretanto, nesse mesmo trabalho (Grisi-Filho et al. 2008), bem como outros autores (Dias et al. 2004), discutem um ponto relevante e que chama a atenção: “... Em algumas subprefeituras, a cobertura vacinal estimada superou $100 \%$, o que não é razoável..." e tecem hipóteses para algumas explicações, todas plausíveis, dentre elas: animais semidomiciliados podem ter sido vacinados ou, então, as estimativas de 1:7 e de 1:46 (cão/habitante e gato/ habitante, respectivamente) podem não ser adequadas para algumas regiões. Inseridas nessas duas hipóteses de Grisi-Filho et al. (2008) há, implicitamente, possível papel importante para o gato na população geral de animais domésticos. E essa suposição deve ser considerada, já que se espera crescimento da população felina, em particular, nas grandes áreas urbanas dos países ocidentais.

Também, percebe-se que o simples uso de recomendações da OMS, sem análise específica da área em questão, pode levar a possível erro, estimando-se equivocadamente a população canina, quando comparada à população humana (Dias et al. 2004, Andrade et al. 2008). Devendo-se ter em mente que, se há mais informações sobre a população canina e, ainda assim, se pode incorrer em erro, o que dizer sobre a população felina, a qual é ainda menos conhecida?

Trabalhos como Childs et al. (1998) e Coleman \& Dye (1996), dentre outros, definem como necessário vacinar de $60 \%$ a $80 \%$ da população canina para se prevenir a infecção. Contudo, essas proporções são calculadas dentro de uma população animal geral, constituída de cães e gatos, nas proporções atuais, e com as características acima consideradas, ou seja, com preponderância maior do cão, mas, e se o gato realmente crescer como se espera?

O Centro de Controle de Zoonoses de São Paulo recomenda, por razões logísticas, um número limite de 700 animais a serem vacinados por posto, preservando, assim, a qualidade da vacinação (Grisi-Filho et al 2008). Entretanto, esse número vem sendo superado, o que pode comprometer a qualidade desse serviço. E com a possível perspectiva de se mudar a proporção do gato na população total vacinada, ou a ser vacinada, há que se adequar a situação para um animal com comportamento e exigências diferentes daquelas do cão.

O objetivo desse trabalho é introduzir debate a respeito da presente e, possivelmente, futura relevância crescente do gato doméstico no que se refere à saúde pública, com ênfase para a raiva (animal e urbana). E também seu potencial crescimento populacional em nosso país, com possível aumento de importância nas proporções de animais vetores.

\section{CARACTERÍSTICAS COMPORTAMENTAIS RELEVANTES DO GATO DOMÉSTICO RELACIONADOS À RAIVA}

Os gatos estão se tornando o mais popular animal de companhia. Em levantamentos feitos nos Estados Unidos, para o ano 2002, registraram-se aproximadamente 76 milhões de gatos e 61 milhões de cães, ou seja, o gato superou seu parceiro de vida doméstica, e não foi apenas nesse país, na China, dentre vários outros países, há outro exemplo, as proporções são ainda mais díspares, pois gatos são encontrados em número ainda maior (53 milhões) do que os cães (23 milhões), ou seja, mais do que o dobro da população. Para nosso país, os números são diferentes, os cães são ainda os mais numerosos (30 milhões) se comparados aos gatos (12 milhões) (Rochlitz 2005). Contudo, essa questão não se limita apenas a números absolutos. A situação específica na qual esses animais se encontram, em cada um desses países, deve ser considerada.

No Brasil, um detalhe importante é que colônias de gatos são muito mais numerosas do que as de cães. Sendo que se deve atentar, particularmente, para aspectos do comportamento do gato, pois a predação sobre morcegos e consequente disseminação de raiva pode se dar de modo muito mais rápido, devido ao elevado aglomerado de colônias felinas. Um dos mais sérios assuntos referentes à saúde pública para os gatos, especialmente para os Estados Unidos e Reino Unido, é a superpopulação (Rochlitz 2005).

É importante destacar que o gato não é "um pequeno cão", ele possui peculiaridades que o caracterizam como animal que necessita de diferentes condições de manutenção e, por conseguinte, apresenta problemas diferentes daqueles observados no cão.

O grau de dependência (dos humanos) que o gato apresenta pode variar amplamente e, nesse aspecto, observa-se importante detalhe a ser considerado, que são as populações ferais, muito comuns entre gatos. Um gato feral pode ser definido de várias maneiras, mas fundamentalmente essa condição de ser feral, ou não, depen- 
derá de sua relação com a população humana. Sua dependência, especialmente para alimento e abrigo, pode ser graduada, concebendo-se a partir de grande dependência (como, por exemplo, um gato mantido num apartamento, que dependerá de seu proprietário para toda e qualquer necessidade) até um gato que nasceu e se reproduz livremente numa ilha ou floresta, totalmente afastado do contato humano (exemplificado o animal feral típico, stricto sensu), e dentre esses dois extremos há ampla gama de gradações.

Como, aqui, baseou-se essencialmente em estudos da América do Norte, em virtude de se constituírem naqueles mais detalhados, percebem-se características preocupantes, pois, da população felina dos Estados Unidos, somente $1 / 3$ dos gatos domiciliados permanecem sob a tutela do mesmo proprietário por toda a sua vida, e a cada ano 1/4 dos gatos adultos deixam seu domicílio, por diversos motivos (Bradshaw 2000), e um desses motivos é o abandono. Ou seja, esses números são especialmente preocupantes se considerar isso uma tendência que pode ser reproduzida também em nosso país.

Uma população crescente de gatos, com características e exigências diferentes daquelas observadas para os cães e, ainda, com essa grande rotatividade de indivíduos circulando pelas ruas em condições de saúde, alimentação e de cuidados gerais impróprias para a espécie e, mais, toda essa situação crítica estará aliada ao grave fato de que a população humana vê esse animal como um elemento 'natural' das ruas, ao mesmo tempo em que, paradoxalmente, tolera-o de maneira muito próxima, dormindo e comendo dentro de suas casas. Todas essas condições somadas podem potencializar a situação de veiculação de zoonoses.

A prevenção é realmente o ponto chave no controle da raiva animal. E os gatos formam aqui um ponto crítico, já que, se realmente a tendência é de que esses animais superem os cães, haverá, então, uma nova realidade a ser enfrentada. Como, até hoje, as campanhas são basicamente voltadas para os cães, novas perspectivas terão de ser consideradas. E já se pode observar que alguns indicadores apontam para a manifestação dessa tendência mundial em nosso país, Campos (2004) relata que gatos são mais abundantes que cães em ambiente suburbano, em estudo desenvolvido em Piracicaba, SP. Outro importante resultado desse estudo é que se pode observar que os gatos, em especial no inverno, encontravam-se reunidos em grupos mais coesos do que os cães, e isso é uma característica comportamental importante a ser considerada, quando se concebe planejamento para vacinação ou mesmo quando se cogita um possível caso de raiva.

Importante aspecto na etologia felina é seu comportamento predatório. Embora as espécies de morcegos hematófagas sejam aquelas realmente relevantes (no aspecto reservatório) para a transmissão da raiva, as insetívoras bem como as frugívoras podem também transmitir a raiva, e essas duas últimas, por motivos de perda de ecossistemas, estão se tornando cada vez mais relevantes na veiculação da raiva (Germano 1994). Grisi-FiIho et al. (2008) ressaltam que a população felina tem grande contato com quirópteros e outros animais silvestres.

Liberg (1984) analisou a dieta de gatos ferais e também com domicílio estabelecido, constatando similaridade na composição das dietas das duas populações. $O$ que vem corroborar a hipótese de que mesmo animais domiciliados podem ter contato significativo com animais silvestres, aumentando a possibilidade de casos de raiva, se somarmos as populações ferais e domiciliadas. Alves et al. (2005) também relatam aumento no percentual de casos positivos no diagnóstico de raiva para a população felina. E, dada a proximidade que esse animal desfruta com seus proprietários e o seu grau de liberdade, colocam-no como um desafio em particular.

Scheffer et al. (2007) argumentam que a presença de vírus da raiva em diversos tecidos de morcegos reforça a possibilidade de transmissão dessa zoonose para animais domésticos que venham a contactar esses espécimes, vivos ou mortos. É interessante lembrar que morcegos infectados podem apresentar paralisia, ou mesmo movimentos desconexos, o que possibilita a exacerbação da atração dessa presa para o gato, facilitando sua captura.

Por fim, outra característica relevante no comportamento do felino doméstico é que essa população oferece maiores dificuldades no quesito controle de liberdade domiciliar, já que a mesma pode se deslocar de modo muito mais efetivo que os cães.

\section{CONCLUSÕES}

O crescente abandono e pouco cuidado que a população humana dedica a seus animais domésticos, em particular nas cidades brasileiras, vem causando preocupação aos responsáveis pela saúde pública (Genaro \& Collucci 2009). Deve-se ter em mente a contínua avaliação desses desafios e o que poderá ocorrer. O controle de agravos, hoje realizado, fundamenta-se na presença do cão como o elemento central, contudo, ao se vislumbrar crescimento significativo da presença do gato, será necessário reavaliar esse segmento da saúde pública, moldando-se as respostas aos novos desafios.

As campanhas de vacinação concebem papel preponderante para o cão, o que reflete a magnitude desse momento e dessa espécie em nosso país, contudo, devido ao crescimento observado no exterior para a população felina, vislumbra-se a possibilidade de mudança de perfil, uma vez que esse crescimento advém das características comportamentais do gato doméstico, que atende as expectativas de vida oferecidas a ele, fruto do estilo de vida ocidental urbano como moradias pequenas e pouco tempo disponível para atender as necessidades do animal. Logo, é necessário preparar uma possível adequação das campanhas de vacinação, já que, atualmente, as mesmas são desenvolvidas em locais a céu aberto, com grande aglomeração de cães (vocalizando), sons de outras ordens (ve- 
ículos etc...) o que dificulta a manipulação do gato, tanto para seu proprietário como para o agente de saúde. Uma sugestão seria a aplicação de estratégia que considerasse as características do comportamento desse animal como um local em separado, com controle de ruídos, fechado, facilitando assim a manipulação do gato e também atendendo a expectativa do proprietário, que percebe o desconforto de seu animal de estimação e, desse modo, tornando-o um aliado no controle dessa grave zoonose.

\section{REFERÊNCIAS}

Alves M.C.G.P., Matos M.R., Reichmann M.L. \& Dominguez M.H. 2005. Dimensionamento da população de cães e gatos do interior do Estado de São Paulo. Revta Saúde Públ. 39(6):891-897.

Andrade A.M., Queiroz L.H., Perri S.H.V. \& Nunes C.M. 2008. Estudo descritivo da estrutura populacional canina da área urbana de Araçatuba, São Paulo, Brasil, no período de 1994 a 2004. Cad. Saúde Pública 24(4):927-932.

Bradshaw J.W.S. 2000. The Behaviour of the Domestic Cat. CABI Publishing, Wallingford, p.177-186.

Campos C.B. 2004. Impacto de cães (Canis familiaris) e gatos (Felis catus) errantes sobre a fauna silvestre em ambientes periurbanos. Dissertação de Mestrado em Ecologia de Agroecossistema. Escola Superior de Agricultura "Luiz de Queiróz", Universidade de São Paulo, Piracicaba, SP. 55p.

Childs J.E., Robinson L.E., Sadek R., Madden A., Miranda M.E. \& Miranda N.L. 1998. Density estimates of rural dog populations and an assessment of marking methods during a rabies vaccination campaign in the Philippines. Prev. Vet. Med. 33(1/4):207-218.
Coleman P.G. \& Dye C. 1996. Immunization coverage required to prevent outbreaks of dog rabies. Vaccine 14(3):185-186.

Dias R.A., Garcia R.C., Silva D.F., Amaku M., Neto J.S.F. \& Ferreira F. 2004. Estimativa de populações canina e felina domiciliadas em zona urbana do Estado de São Paulo. Revta Saúde Públ. 38(4):565-570.

Genaro G. \& Collucci E. 2009. Posse responsável de animais de estimação. Ciência Hoje 44(260):68-69.

Germano P.M.L. 1994. Avanços na pesquisa da raiva. Revta Saúde Públ. 28(1):86-91.

Grisi-Filho J.H.H., Amaku M., Dias R.A., Netto H.M., Paranhos N.T. \& Mendes M.C.N.C. 2008. Uso de sistemas de informação geográfica em campanhas de vacinação contra a raiva. Revta Saúde Públ. 42(6):1005-1011.

Liberg O. 1984. Food habits and prey impact by feral and housed-based domestic cats in a rural area in southern Sweden. J. Mammal. 65:424432.

Miranda C.F.J., Silva J.A. \& Moreira E.C. 2003. Raiva humana transmitida por cães: áreas de risco em Minas Gerais, Brasil, 1991-1999. Cad. Saúde Pública 19(1):91-99.

Neto V.A. \& Pasternak J. 2008. Pesquisas: prioridades para a nossa saúde pública. Revta Saúde Públ. 42(5):972-973.

Passos A.D.C., Silva A.A.M.C.C., Ferreira A.H.C., Silva J.M., Monteiro M.E. \& Santiago R.C. 1998. Epizootia de raiva na área urbana de Ribeirão Preto, SP, Brasil. Cad. Saúde Pública 14(4):735-470.

Rochlitz I. 2005. The Welfare of Cats. Springer, Dordrecht, p.49-81.

Scheffer K.C., Carrieri M.L., Albas A., Santos H.C.P., Kotait I. \& Ito F.H. 2007. Vírus da raiva em quirópteros naturalmente infectados no Estado de São Paulo, Brasil. Revta Saúde Públ. 41(3):389-395.

Schneider M.C., de Almeida G.A., Souza L.M., Morares N.B. \& Diaz R.C. 1996. Controle da raiva no Brasil de 1980 a 1990. Revta Saúde Públ. 30(2):196-203. 